\title{
Patrimonialização e afirmação cultural no distrito de Olhos d'Água, Goiás, Brasil
}

\author{
Fernando Luiz Araújo Sobrinho ${ }^{1}$ \\ Edilene Américo Silva ${ }^{2}$
}

\begin{abstract}
Resumo: Em 1960, o distrito de Olhos d’Água, no estado de Goiás (Brasil), perdeu a condição de Sede política para a recém-construída Alexânia, às margens da rodovia BR-060 de sua econômica e esvaziamento demográfico. Porém, a partir de 1974, por meio da Feira do Troca, Olhos d'Água conseguiu projetar-se como resistência cultural no contexto estadual. Tanto a Feira, que é considerada patrimônio imaterial local, quanto o povoado têm sido inseridos no turismo municipal e estadual por meio de um processo de patrimonialização resultante de lógicas locais de comércio, consumo e circulação que são produtos da nova dinâmica econômica global. A Feira, o sítio histórico, a produção artesanal e o modo de vida da comunidade são singularidades que atraem cada vez mais um número maior de visitantes. A pesquisa indicou que há um processo de turistificação em curso que coloca em discussão tanto a necessidade de fortalecimento local, quanto a de conservação do conjunto arquitetônico local.
\end{abstract}

Palavras-chave: Feira do Troca, Olhos d'Água, Patrimônio material e imaterial.

\section{Patrimonialización y afirmación cultural en el distrito de Olhos d’Água, Goiás, Brasil}

Resumen: En 1960, el distrito de Olhos d'Água, en el estado de Goiás (Brasil), perdió la condición de Sede política para la recién construida Alexânia, a los márgenes de la carretera BR 060 de su económica y vaciamiento demográfico. Sin embargo, a partir de 1974, por medio de la Feria del Cambio, Olhos d'Água consiguió proyectarse como resistencia cultural en el contexto estadual. Tanto la Feria, que es considerada patrimonio inmaterial local, cuanto el pueblo ha sido insertado en el turismo municipal y estatal por medio de un proceso de patrimonialización resultante de lógicas locales de comercio, consumo y circulación que son productos de la nueva dinámica económica global. La Feria, el sitio histórico, la producción artesanal y el modo de vida de la comunidad son singularidades que atraen cada vez más un número mayor de visitantes. La investigación indicó que hay un proceso de turistificación en curso que pone en discusión tanto la necesidad de fortalecimiento local, como la de conservación del conjunto arquitectónico local.

Palabras clave: Feria del Cambio, Olhos d'Água, Patrimonio material e inmaterial.

\section{Patrimonialization and cultural affirmation in Olhos d'Água district, Goiás, Brazil}

Abstract: In 1960, the district of Olhos d'Água, in the state of Goiás (Brazil), lost the status of Political Seat for the newly built Alexânia, on the BR 060 highway for its economic and demographic depletion. However, from 1974, through the Trade Fair, Olhos d'Água was able to project itself as a cultural resistance in the state context. Both the Fair, which is considered local intangible heritage, and the village have been inserted in the municipal and state tourism through a process of patrimonialization resulting from local logics of trade, consumption and circulation that are products of the new global economic dynamics. The Fair, historical site, craft production and the way of life of the community are singularities that attract more and more visitors. The research indicated that there is an ongoing process of tourism that puts in discussion both the need for local strengthening and the conservation of the local architectural complex.

Keywords: Feira do Troca, Olhos d'Água, heritage material and immaterial.

Recebido: janeiro de 2018. Aceite: março de 2018.

${ }^{1}$ Doutor em Geografia pela Universidade Federal de Uberlândia (UFU) e docente do Programa de Pós-Graduação em Geografia/PPGEA, da Universidade de Brasília (UnB). Email: flasobrinho@gmail.com

${ }^{2}$ Doutora em Geografia pela Universidade de Brasília (UnB) e docente do Instituto Federal de Brasília/IFB. Email: edileneamerico@hotmail.com 


\section{Introdução}

A noção de patrimônio cultural tem ganhado robustez, progressivamente, ao longo do século XX. Para Costa (2010), a partir da Segunda Grande Guerra, passou-se a valorizar essa noção em sua perspectiva de conjunto e o patrimônio histórico foi reconhecido como material e imaterial. E essa concretude ou representação advém da herança cultural das comunidades nas ações locais de interação com seu espaço de reprodução. Disso decorrem os sentidos, os "objetos e os fixos" (Santos, 2004) como algo que "identifica as pessoas com seu território" (Haesbaert, 2004) e na construção da própria história.

O presente estudo foi realizado no distrito de Olhos d'Água que está localizado no município de Alexânia, no estado de Goiás. Durante décadas, esse distrito sofreu poucas influências dos processos modernizadores, resultantes dos circuitos escalares oriundos da urbanidade entre Brasília e Goiânia - as duas cidades mais dinâmicas do Centro Oeste do país. Essas poucas influências podem ter relação com dois aspectos: a distância geográfica, 14 quilômetros da comunidade em relação a BR-060 - cujos fluxos dela resultante repercutem sobre a economia da Sede municipal, Alexânia; e também dos baixos investimentos públicos que pouco contribuíram para a inserção do distrito no circuito regional da economia goiana.

Por seu turno, esse "tempo lento" (Santos, 2004) que marca o cotidiano de Olhos d'Água foi essencial para a produção de um patrimônio cultural com significado irreplicável no contexto regional do estado. Os casarios, o sítio histórico, as comidas típicas, a Feira do Troca, a produção artesanal, as festas sagradas e profanas realizadas pelos moradores decorrem de um processo histórico de relação das pessoas com o seu lugar de vida. Em conjunto, esse patrimônio torna-se, na atualidade, essencial à comunidade em virtude da função social que desempenha. Para Costa (2010), a importância do patrimônio também reside no sentido de memória e na construção indentitária local. E em Olhos d'Água, o resultado desses sentidos mediatiza a ação da comunidade influindo na configuração estrutural do território em construção.

O presente estudo resulta de uma pesquisa qualitativa, cujos dados e informações foram obtidos por meio de levantamentos bibliográficos e de atividades de campo. Nessa etapa, além das observações in loco, procedeu-se com o registro fotográfico e a aplicação de questionários com perguntas semiestruturadas. Realizou-se, ainda, um campo de imersão que teve o propósito de aproximar-se ainda mais da problemática em estudo. E a estratégia de realizar o levantamento histórico do processo de ocupação, desde a origem, foi atingida por meio de estratégias indicadas em pesquisas etnográficas.

Investigou-se o fenômeno de patrimonialização de Olhos d'Água e como esse patrimônio material e imaterial contribui na afirmação cultural das famílias em seu lugar de vida. Essa comunidade, desde o evento que resultou na perda da Sede política em favor de Alexânia (em 1961), viveu momentos de desarticulação - econômica e política. Entretanto, a partir da realização de um projeto de arte e educação desenvolvido na escola local, os moradores identificaram que o resgate dos saberes tradicionais, reelaborados sob nova perspectiva, poderia conduzi-los a novo patamar de destaque no contexto tanto municipal quanto estadual.

Tal cenário estimulou a organização local em torno da produção artesanal e da valorização das festas, da feira, da culinária, dos casarios e do sítio histórico. Esses elementos constituem parte do patrimônio cultural que ratifica a identidade e memória das pessoas com seu lugar de vida. Entretanto, entre estas expressões culturais, procedeu-se com um recorte da Feira do Troca como aquela que melhor identifica a comunidade com seu lugar. Ela representa a superação e o protagonismo dos moradores na construção de sua história, no contexto municipal alexaniense.

O objetivo do presente estudo foi identificar as expressões culturais - materiais e imateriais -, resultantes do cotidiano da comunidade de Olhos d'Água que se tornaram patrimônio cultural local. Por meio das pesquisas aplicadas, identificou-se que, não obstante tantas outras representações culturais, a Feira do Troca foi escolhida - pelos moradores -, como o evento mais importante na condução da comunidade para a superação da condição de introspecção e desarticulação em que esteve mergulhada, entre os anos de 1961 até 1973. E com a realização da primeira Feira do Troca, em 1974, o distrito iniciou a sua projeção como resistência cultural regional.

$\mathrm{Na}$ atualidade, a comunidade identifica que o futuro de Alexânia passa, necessariamente, pela história cuja gênese se deu em Olhos d'Água. E voltar às origens conduz ao movimento de enxergar o lugar em que os sujeitos se reconhecem em sua própria história para reviver os elementos identitários sob um novo olhar e em outro tempo (Silva, 2016).

Entretanto, a turistificação da comunidade desperta a necessidade tanto de fortalecer o local quanto de preservar seu patrimônio cultural, pois a crescente mercantilização das expressões culturais tem envolvido o patrimônio cultural em uma lógica dialética de uma construção destrutiva conforme 
Fernando Luiz Araújo Sobrinho Edilene Américo Silva

discute Costa (2010) em suas reflexões. Nesse processo, os bens culturais têm seus sentidos metamorfoseados em prol da indústria cultural do turismo.

\section{O município de Alexânia}

Esse município goiano está situado na Região do Entorno do Distrito Federali. Segundo o Instituto Brasileiro de Geografia e Estatística IBGE (2015), suas coordenadas geográficas são $16^{\circ}$ 04' 12" de latitude sul e $48^{\circ} 31$ ' 12 " de Longitude oeste, com área total de 847,89 quilômetros quadrados, conforme expressa a figura 1, que mostra a localização municipal. Informações desse órgão indicam que a população total deste município é de, aproximadamente, $26.135 \mathrm{mil}$ moradores (IBGE, 2015). nacional. No contexto municipal alexaniense, as principais repercussões da implantação daquele modal foram: a criação da cidade de Alexânia, na borda da rodovia, em 1961; o deslocamento do eixo de desenvolvimento municipal para essa nova cidade; e a perda da sede municipal de Olhos d'Água em favor de Alexânia.

Para a comunidade de Olhos d'Água, as consequências resultantes da perda da condição de Sede municipal repercutiram tanto na sua organização econômica quanto nos arranjos produtivos que sofreram rupturas levando à desarticulação produtiva desse distrito. Nos anos seguintes, teve-se o declínio e posterior estagnação que perdurou nos anos seguintes, até 1974, ano de rearticulação da comunidade, por meio da Feira do Troca.

Figura 1. Localização de Alexânia - Goiás.

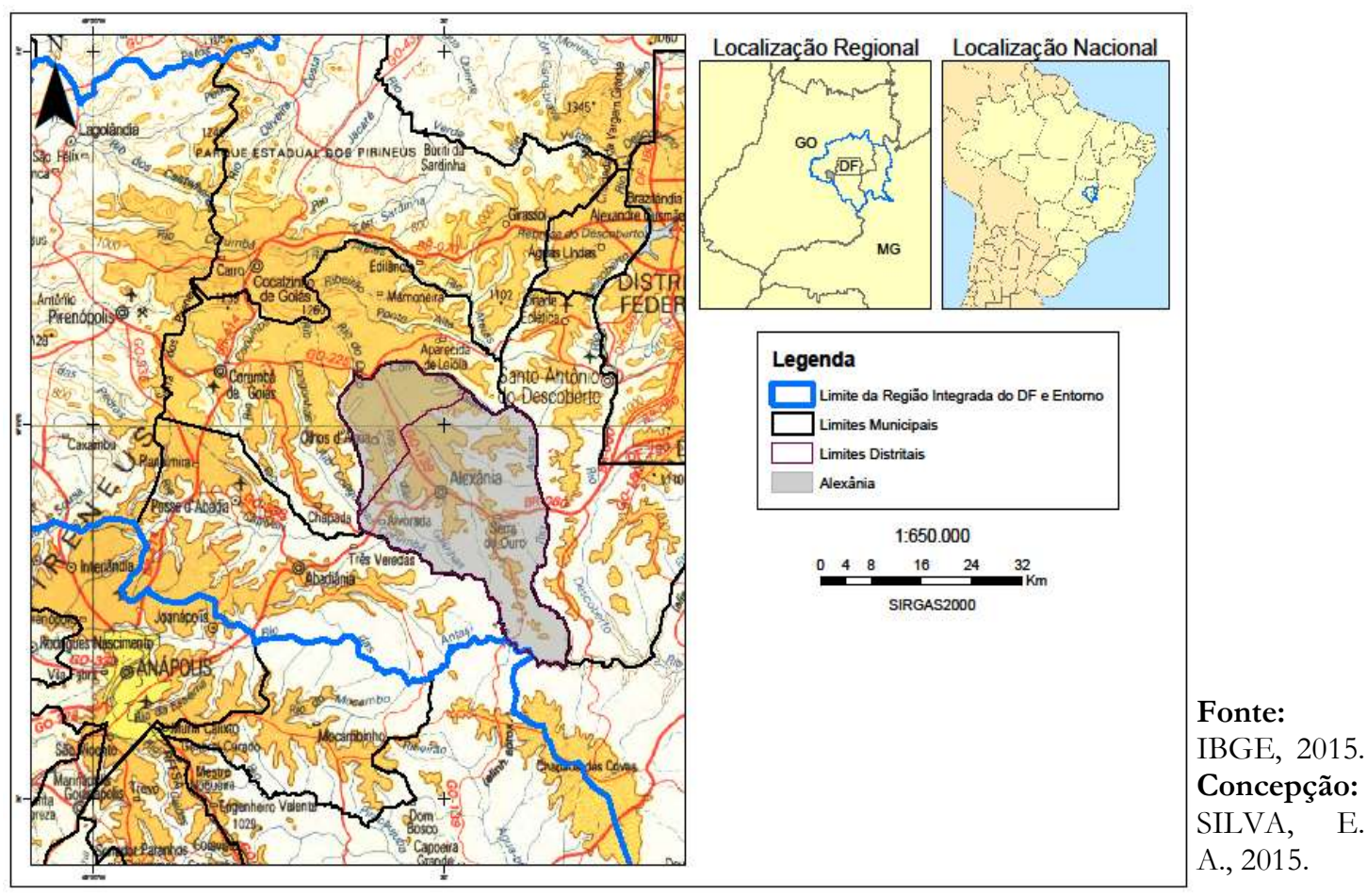

É estratégica a centralidade de Alexânia, Sede municipal, que está situada a 92,4 quilômetros da capital do estado e a 120,9 quilômetros de Brasília. Em virtude disso, o município beneficia-se dos fluxos urbanos gerados por essas duas importantes economias do Brasil central (Silva, 2017).

A gênese daquela cidade adveio da construção da rodovia BR-060 que corta, perpendicularmente, o território municipal. Por sua vez, a construção dessa rodovia resultou da edificação de Brasília, na década de 1950, como ação do Estado voltada à integração do território
Assim, a mudança da Sede municipal para Alexânia até hoje é relembrada e contada em tons de ressentimento pelos moradores mais velhos de Olhos d'Água. Tal realidade resultou em alguns prejuízos ao desenvolvimento socioeconômico atual da comunidade destacando-se: ausência completa de transporte público de passageiros, entre Olhos d'Água e Alexânia, para condução diária; poucos postos de trabalho e emprego à população economicamente ativa; ausência de capacitação de mão de obra; e migração intensa da população mais jovem para cidades vizinhas em busca de emprego e formação. 
Fernando Luiz Araújo Sobrinho

Edilene Américo Silva

Os moradores locais entrevistados disseram que a falta de interesse do governo municipal em realizar investimentos voltados ao bem estar da comunidade tem sido recorrente nas diversas administrações. Informaram também, que há muito tempo aqueles moradores que têm interesse em estudar ou trabalhar precisam buscar essas condições fora da comunidade, através da migração pendular ou definitiva, quando se dirigem para as cidades de Brasília, Goiânia e Anápolis, que oferecem oportunidades de emprego e estudo.

\section{O distrito de Olhos D’Água: origem e evolução}

As discussões acima indicam que a origem do município de Alexânia se deu no distrito de Olhos d'Água, que dista 14 quilômetros daquela Sede, e cujo acesso ocorre por estrada pavimentada. Os primeiros registros da ocupação deste distrito datam do ciclo da mineração em território goiano - século XVIII, e, posteriormente, com as fazendas de gado e da agricultura. Já nos primeiros decênios do século $\mathrm{XX}$, as famílias trabalhavam para três grandes fazendeiros locais em troca de moradia e um pouco de comida (Silva, 2017).

Desde então, passou a crescer o povoado de Santo Antônio de Olhos d'Água que, nessa época, pertencia ao atual município de Corumbá de Goiás. Assim, no período de 1910, teve-se o início do povoamento e, até fins da década de 1950, o núcleo consolidou-se como distrito a ser transformado em município e Sede, política e administrativa, no ano de 1958 (IBGE, 2010).

$\mathrm{Na}$ origem da ocupação, as famílias foram desenvolvendo um modo de vida próprio. Para manterem-se e alimentarem-se elas plantavam milho, feijão, arroz, mandioca, ervas aromáticas, algodão, fumo e mantinham pequenas criações. Organizavam seus arranjos produtivos locais que se tornaram autossuficientes às demandas dos moradores (Silva \& Araújo Sobrinho, 2016).

Além disso, produziam, para seu uso utensílios - de madeira e barro - como panelas, potes e artigos de tecelagem. E o isolamento do povoado, associado a sua capacidade produtiva, contribuiu para que as pessoas criassem um modo de vida próprio. Tornaram-se autossuficientes na produção de gêneros alimentícios de primeira necessidade; fiavam e teciam as próprias roupas e faziam os utensílios de que necessitavam gamelas, colheres de pau e cestas, além de construírem suas próprias casas. O contato com outras comunidades se dava, esporadicamente, por intermédio de viajantes que traziam para trocar o que ali não era encontrado, ratificam os autores.
Destarte, a transformação de Olhos d'Água em município, em 1958, contribuiu ainda mais para sua consolidação territorial e tanto a agricultura quanto o artesanato foram as atividades propulsoras da economia local. Desde a origem, até meados da década de 1960, Olhos d'Água era autossuficiente em razão do "povo produzir tudo de que necessitava e só trazer de fora o sal, que vinha de Minas Gerais" (http://olhodogoias.blogspot.com.b r/2009/02/primeira-casa.html, recuperado em 15 de setembro, 2014).

Todavia, em 1961, esse processo foi interrompido pela transferência das funções administrativas para a nova Sede, Alexânia, que também representava o ideário municipal de modernidade. A sua localização estratégica na borda da nova BR-060 beneficiaria o desenvolvimento municipal pela frequência e intensidade dos fluxos resultantes da presença da rodovia que ligaria as duas cidades mais importantes do interior do Brasil - Brasília e Goiânia (Silva, 2016).

Resultou, então, que a perda da condição de Sede municipal trouxe prejuízos à organização produtiva local. Alguns moradores venderam suas propriedades, abandonaram as lavouras e se mudaram para a nova Sede onde passaram a comercializar ou realizar atividade econômica diversa.

Nesse cenário, os arranjos produtivos locais sofreram rupturas que levaram à desarticulação da economia local (Silva \& Sobrinho, 2017). Assim, o desafio posto era desenvolver novas possibilidades econômicas que contribuíssem para reversão da estagnação econômica, social e política em que a comunidade passara a viver.

Entretanto, transcorreram-se alguns anos e foi apenas após 1973 que as famílias despertaram e reconheceram a necessidade de valorização da própria identidade por meio do resgate dos seus valores culturais, das crenças e da elaboração artesanal. Nessa perspectiva, ações foram empreendidas no desenvolvimento do projeto de Arte e Educação executado por meio de uma Escola localii.

Nesse contexto, teve-se a produção de cerâmicas e artesanatos em palha, em tecidos e em madeira; e a preparação e realização de festas gestadas no âmbito da própria comunidade. Nesses ajuntamentos e reuniões, entre moradores, a memória e o saber local eram materializados na preparação das danças, das músicas e dos alimentos. E todas as festas - religiosas e profanas resultavam de um processo que tinha origem na produção agrícola e no cotidiano local, que possibilitavam o repasse dos conhecimentos às novas gerações. 
Fernando Luiz Araújo Sobrinho Edilene Américo Silva

Sobre os festejos Pelegrini (2009) afirma que as festas e as cantigas a elas associadas são sons que fazem aflorar sensibilidades que nos reportam para histórias de um tempo pretérito e, simultaneamente, presente nas redes de sociabilidades da comunidade. No caso de Olhos d'Água, os festejos são expressões entrecortadas por caminhos que dialogavam com os sentidos do lugar, que levam a comunidade a se reconhecer como parte essencial da nova conjuntura política municipal; não como ideário de modernidade, mas enquanto memória viva do município.

Segundo aquele autor, os artesãos também constituem patrimônio cultural local e conformam a memória viva de dada comunidade, ou seja, eles conjugam representações da memória social local. Por meio das entrevistas realizadas, percebeu-se que as peças artesanais traduzem o saber dos antepassados, seja através dos materiais usados matéria prima e base da produção - ou por meio das cores, formas e padronagens que refletem também as crenças e valores tradicionais. E mesmo a inspiração para a produção dos artefatos resulta do cotidiano local. minha produção; que me inspira" (Informação verbal, 2016).

$O$ contexto assinalado indica que, na comunidade em estudo, em tempos pretéritos, o modo de vida das famílias era reflexo de sua relação com seu lugar de vivência. E no transcurso do tempo resultaram em elementos e expressões que se materializaram localmente nas festas religiosas, na culinária, nos artefatos e utensílios produzidos pelos primeiros moradores, cuja função e simbolismo foram compartilhados com seus descendentes. Essas referências identitárias foram essenciais e constituíram-se em elos que vincularam as gerações futuras aos seus marcos históricos ligados ao lugar. E nem mesmo a perda da Sede política e administrativa, em favor de Alexânia, foi capaz de apagar esses referenciais identitários. As pessoas encontraram na cultura o elo comum que fortaleceu e propiciou a retomada de sua história e a resistência comunitária no contexto municipal alexaniense.

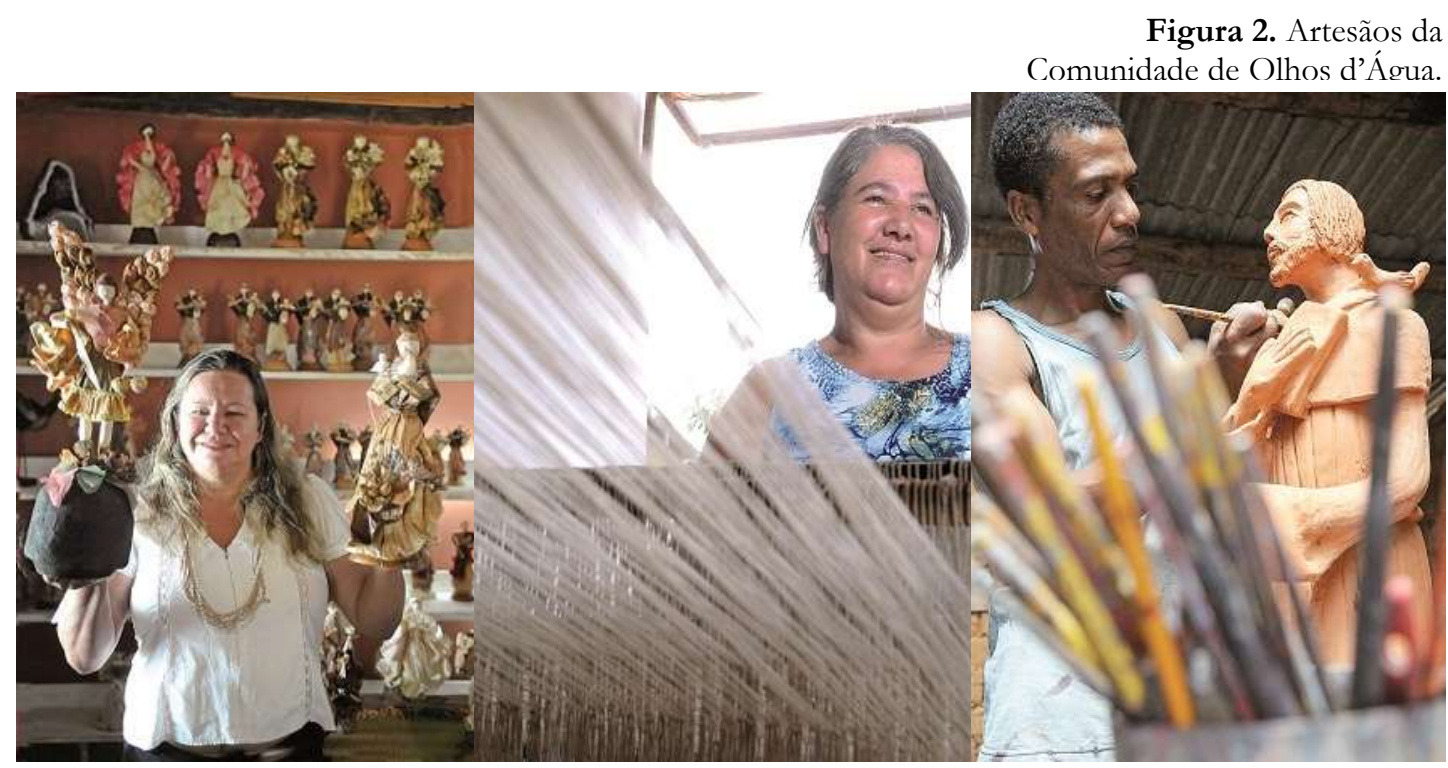

Fonte: Correio Brasiliense (2015). Legenda: Da esquerda para a direta: Fatinha, Madalena e Lourenço.

$\mathrm{Na}$ figura 2, observam-se alguns dos principais artesãos de Olhos d'Água que fizeram parte, quando crianças, do projeto de arte e educação desenvolvido na escola local. Atualmente, são lideranças comunitárias e referências regionais na produção artesanal do município de Alexânia.

A artesã Fatinha relatou que em todos os eventos, estaduais ou internacionais que participa se apresenta como Fatinha de Olhos d’Água. Ela diz ser mais significativo para si. "Não sou Fatinha de Alexânia; sou a Fatinha de Olhos d'Água. Tudo começou aqui; Olhos d'Água veio antes de Alexânia e é esse lugar que permite a

\section{Patrimônio Cultural: função social, identidade e memória em construção}

Antes de adentrarmos na discussão sobre patrimônio cultural e patrimonialização em Olhos d’Água, convém apresentar uma rápida evolução da noção desse termo. Patrimônio cultural é um conceito mais recente que, no transcurso do tempo, tem evoluído, lenta e gradualmente, com o fim de abranger um sentido conceitual mais ampliado. De acordo com Costa (2010, p. 51), os significados atribuídos a essa materialidade, ao longo de um processo histórico, resultam da 
Fernando Luiz Araújo Sobrinho Edilene Américo Silva

necessidade de que o termo envolva "uma gama de objetos, ritos e significados que abarque a superposição de conceitos e práticas culturais envoltas na trajetória de sua construção ao longo do tempo".

Para Mohen (1999), a origem dessa noção partiu da ideia de monumento enquanto objeto isolado a ser contemplado e preservado, até a concepção mais recente, que cobre, de maneira complexa, diversos bens e tesouros do passado, materiais e imateriais. Assim a expressão patrimônio cultural, enquanto conjunto do que é transmitido consciente e inconscientemente pelos homens tem sua origem no século do iluminismo, adquirindo força jurídica durante o século XIX, enquanto patrimônios criados paralelamente à construção das nacionalidades de diversos países europeus.

Nessa perspectiva, Costa (2010, p. 38) trata da consagração do patrimônio mundial partindo do processo histórico de ampliação da noção de patrimônio e dos significados atribuídos a essa materialidade, ao longo do tempo, nas cidades, até se tornar uma "mercadoria mundial (des)localizada".

Com isso posto, depreende-se que a noção de patrimônio cultural têm ganhado robustez progressivamente ao longo do século XX; a "partir do pós-guerra valoriza-se a noção de conjunto e a superação da arquitetura como obra de arte independente e isolada. De monumento a patrimônio histórico, centro histórico, patrimônio cultural, que por sua vez é reconhecido como material e imaterial" (Costa, 2010, p. 52). Desde então, teve-se o início de uma nova política de resgate do passado, da valorização dos centros históricos e da ampliação de definições conceituais. Para Arjona (1986, p. 11), desde então, a "identidade do objeto como valor de referência foi a expressão assumida para reconhecer-se, ou seja, para identificar-se com aquilo que forma parte da sua história". Para o autor deve-se tomar patrimônio material e imaterial como complementares, faces de uma mesma moeda: a do patrimônio cultural.

Entretanto, Costa (2010, p. 50) reforça que foi apenas "na segunda metade do XX que as manifestações populares começaram, gradualmente, a serem vistas como bens patrimoniais em si, sem que objetos fossem convocados a ratificá-las". Para Sant'Anna (2010), essa prática de preservação não tem origem primária na Europa, mas em países asiáticos e no então chamado Terceiro Mundo, cujo patrimônio, em grande medida, é constituído das criações populares, menos importantes na materialidade, sendo vinculadas diretamente ao conhecimento popular, práticas populares e processos culturais.
À luz dessas reflexões, pretende-se apresentar a comunidade de Olhos d'Água como patrimônio cultural, tanto material quanto imaterial, com forte expressividade territorial no contexto municipal de Alexânia. Isso porque, essa comunidade, após vivenciar momentos de introspecção e desarticulação política, conseguiu reafirmar sua importância através da reinvenção das festas tradicionais e da produção artesanal resultante dos saberes originários local - todos reproduzidos agora sob forte influência de perspectivas culturais contemporâneas.

Nossa análise parte da utilização do termo patrimônio cultural por compreender que ele contém uma noção mais ampliada de patrimônio. Para Costa (2010, p. 51), esse termo "abrange a superposição de conceitos e práticas culturais envolvidas na trajetória de sua construção ao longo do tempo".

Para o autor, tal a análise não se desvencilha, por um lado, do mistério imaterial que o ronda, do invisível que o permeia, de sua força memorial, de seu conteúdo significativo escondido em suas formas. Por outro lado, não se "desvencilha, tampouco, das transformações do seu valor simbólico, dos novos sentidos a ele atribuído, por meio de sua apropriação estratégica pela indústria cultural. (p. 51). Desse modo o autor afirma que patrimônio cultural - material e imaterial - "engloba tudo que é dotado de significado cultural irreplicável. É um referencial de memória viva" (Costa, 2010, p. 56).

Nessa linha de reflexão, toma-se a comunidade de Olhos d'Água - os casarios e o sítio histórico - como patrimônio cultural material. Já as manifestações culturais (comidas típicas, festividades e a Feira do Troca) são tomadas como patrimônio cultural imaterial. Em conjunto, essa materialidade é essencial à comunidade sob três principais facetas: à função social; ao sentido da memória; e, também, na construção identitária e na configuração estrutural do território, este nos permite estabelecer um diálogo com Costa (2010).

Em referência à função social, o patrimônio cultural de Olhos d'Água contribui no fortalecimento do sentimento de pertencimento ao lugar e, também, na edificação da cidadania. As entrevistas realizadas indicaram que a comunidade reconhece a necessidade de recuperação da própria identidade e dos valores culturais por meio da preservação dos casarios e do sítio histórico local. Além destes, citam também as festividades como a Feira do Troca e as Festas do Divino e da Quadrilha Junina. São ajuntamentos precedidos de preparação que envolve os sistemas produtivos agropecuários - que se constituem em insumos à elaboração de alimentos -, peças artesanais, danças, poesias, cantigas e músicas. 
Fernando Luiz Araújo Sobrinho Edilene Américo Silva

Quanto ao sentido da memória da tradição e da cultura, a memória, enquanto patrimônio cultural, está associada à disposição de retenção e armazenamento de informações, sentimentos e imagens constituintes da identidade individual e coletiva. Ao que Pelegrini (2009, p. 33) afirma que essas indentidades referem-se as "culturas e aos modos de entender o mundo, condição essencial para a continuidade das práticas culturais e para a reconstrução em si desse processo".

Em referência a última faceta, o patrimônio material e imaterial indicado, na comunidade em estudo, reforça a construção da identidade e da consciência de pertencimento ao local, que possui sentido no papel individual de construção coletiva dos moradores com seu espaço de vida. Para aquele autor, a proteção do patrimônio natural, das paisagens e dos bens culturais (móveis ou imóveis, materiais ou imateriais) resulta diretamente na melhoria da qualidade de vida da população, pois a preservação das memórias e das identidades é uma demanda social tão importante quanto qualquer outra atendida pelo serviço público.

Destarte, o patrimônio em Olhos d'Água reforça a tradição local que é continuamente recriada. Entretanto, em diálogo com Castriota (2009), aqui a tradição não seria vista como uma dimensão cristalizada, imóvel da cultura, ou seja, o presente a repetir o passado através daquilo que dele herdou. Ao contrário, a memória enquanto tradição cultural dialoga com a "plasticidade da cultura", ao apontar para o fato de que todos os sistemas culturais, mesmo aqueles tradicionais, estão em contínuo processo de modificação.

Desse modo, nesse contínuo processo de modificação cultural Castriota (2009, p. 22) indica que "não haveria uma cultura estática, e o próprio processo de transmissão incorporaria possibilidades de mudanças, através das quais as culturas se mantêm flexíveis e podem absorver as inevitáveis variações trazidas pelo tempo". É nesse diálogo que se observa as novas aderências que recebem as expressões culturais em Olhos d'Água: na festa, na produção artesanal ou na culinária. Essas transformações resultam do contato intercultural que representa o grande motor do avanço das culturas que, em diálogo, conseguem incorporar elementos trazidos das outras culturas.

Por fim, o patrimônio cultural de Olhos d'Água tem sido essencial para a construção identitária e a configuração estrutural do território local. Nesse sentido, a formação da identidade local parte daquela perspectiva discutida por Pelegrini (2009, p. 32) que afirma ser ela formada a partir de um
Patrimonialização e afirmação cultural no distrito de Olhos d’Água, Goiás, Brasil

Processo contínuo e complexo de construção do 'sujeito' individual em relação ao outro, de constituição de identidades grupais definidas por meio de critérios como a aceitabilidade e a credibilidade que se afirmam por meio de negociacões diretas com os outros e seus respectivos universos culturais, tornando-os reciprocamente unificados diante de determinado interesses.

Nesse diálogo, Arjona (1986, p. 13) afirma que a identidade cultural está expressa como uma

consequência e não como um objeto em si: se conserva isso porque nos reconhecemos no patrimônio e a consciência de reconbecer-se bistoricamente em seu próprio entorno, físico e social, cria um caráter ativo da identidade cultural pela ação de conservação que isso gera.

Resulta, então, que o princípio da identidade cultural se produz através do patrimônio e também como uma conseqüência dele. Desse modo, dentre as representações patrimoniais da comunidade, daremos relevo a Feira do Troca que, por meio das entrevistas realizadas, foi indicada como o evento emblemático que melhor traduz a história da luta das famílias pelo resgate de sua cultura local. Os depoimentos indicaram que, depois da Feira, a comunidade reconquistou sua estima e seu lugar de destaque no contexto municipal, pois o evento além de mobilizar as famílias locais, em sua organização, também atrai centenas de pessoas de todo o estado. E, durante os dias do evento, há enorme visitação de turistas que movimentam a economia local. Some-se a isso a participação de muitos artesãos e produtores que vêm comercializar suas mercadorias. A feira ocorre duas vezes ao ano e tem enorme força de mobilização de toda a comunidade, que participa de todo o processo - da produção artesanal e cultural, do planejamento e execução do evento.

\section{O papel da Feira do Troca como patrimônio cultural em Olhos D’Água}

Embora o início do povoamento em Olhos d'Água date da primeira metade do século XX, o padrão arquitetônico colonial serviu de inspiração para as primeiras edificações locais. Sobressai o bom estado de conservação das edificações, os tons coloridos das casas e a sua disposição espacial em torno de uma ampla área gramada e arborizada, que tem ao centro uma igreja e um cruzeiro, como observado na figura 3.

A arquitetura das edificações, a disposição das ruas e a característica pacata e tranquila da 
Fernando Luiz Araújo Sobrinho Edilene Américo Silva

cidade criam um ar interiorano e brejeiro. Esse conjunto material desperta o interesse daquele visitante urbano acostumado ao concreto e ao asfalto predominante nas grandes cidades.

Além da paisagem bucólica chamam a atenção, ainda, a produção artesanal, as festas e a cultura alimentar que passaram a ser valorizadas também pelas famílias locais, quando enxergaram que a importância da comunidade residia na sua história e memória. Assim, identificaram que precisavam rememorar, festejar e repassar esses valores às novas gerações.
Patrimonialização e afirmação cultural no distrito de Olhos d’Água, Goiás, Brasil

Goiânia, Abadiânia, Anápolis, Cocalzinho de Goiás, Corumbá de Goiás, Santo Antônio do Descoberto, Pirenópolis, Águas Lindas e Valparaíso.

Figura. 3 - Vista da área central de Olhos d'Água: casarios e igreja.

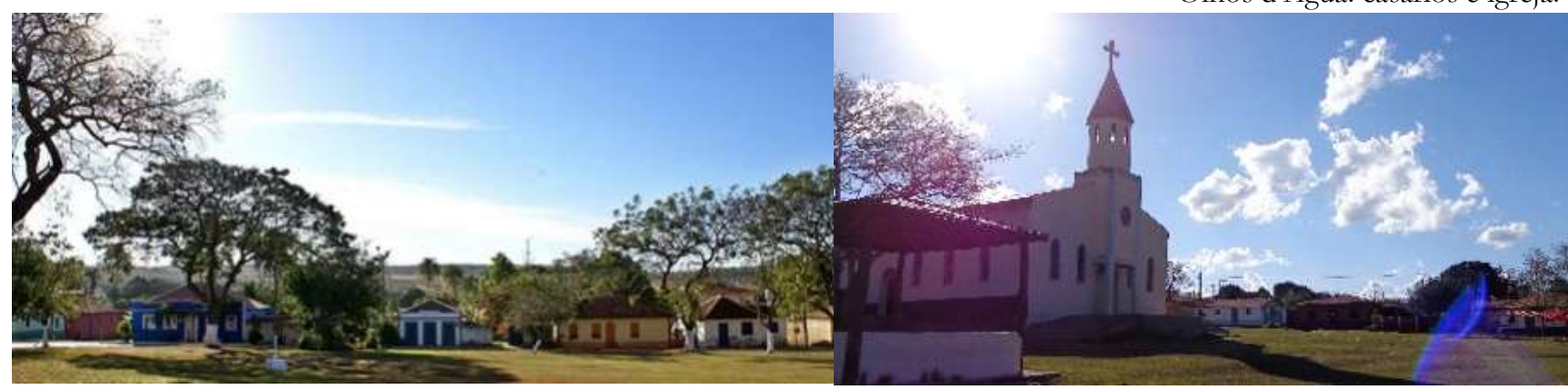

Fonte: SILVA, E. A., 2015.

Para além da Feira do Troca, consideram-se também como marcos identitários a culinária representada pelo arroz-com-pequi; o artesanato em cerâmica, metal e pedra; as toalhas tecidas nos teares familiares - que são alimentados por fios produzidos a partir do algodão plantado e colhido pelos moradores; as bonecas de pano adornadas com roupas e cabelos coloridos; as peças em argila; e, as imagens sacras confeccionadas com a palha do milho cultivado na própria comunidade. Essa produção artesanal é permanente e destinada a outros espaços de exposição e comercialização externos a Olhos d'Água.

É nesse cenário que se constrói a identidade cultural da comunidade com seu espaço de reprodução. No bojo desse movimento, tem-se também instalada uma dinâmica socioespacial, que resulta e reflete na relação entre os sujeitos sociais aí presentes com seu lugar de vida. Assim, estabeleceram-se processos de constituição territorial que conduz, de modo crescente, o sentido de pertencimento com o lugar.

Por meio das entrevistas realizadas e de pesquisas junto ao site da comunidade constatou-se que a Feira do Troca ocorre duas vezes ao ano, no primeiro domingo dos meses de junho e dezembro. A Feira, como expressão identitária local, possui alcance regional. Durante a realização do último evento, no mês de dezembro de 2014, identificamos pessoas que vieram das cidades de Brasília (DF) e dos seguintes municípios goianos:
Esse evento resulta da participação das famílias que, até os dias atuais, realizam a atividade como forma de manterem suas tradições e se autoafirmarem para além da esfera municipal. A primeira Feira ocorreu em dezembro de 1974 e nela os produtos da "roça" eram trocados pelos produtos da "cidade", atendendo ao objetivo do

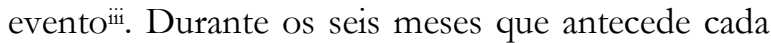
feira, a comunidade se prepara. Empreende esforços tanto na produção de cultivos agrícolas quanto na elaboração de peças artesanais, para venda e troca durante os três dias de realização das festividades associadas ao evento, que começa sexta a noite estendendo-se até domingo a tarde. Nesses dias ocorrem exposições de danças, músicas e comidas tradicionais. E a comunidade, que possui em torno de 1.445 pessoas (IBGE, 2010), fica tomada por quase 5 mil visitantes de cidades próximas, conforme a Figura 04 a seguir, que retrata a realização da feira em junho de 2016.

A Feira ocorre na praça da cidade e esse espaço é um local de encontro e confraternização entre moradores e visitantes. Ao olhar do visitante desatento, que não guarda relações de pertencimento com a comunidade, talvez a feira pareça mais um espaço de consumo transplantado para uma área singular - a bucólica comunidade ou seja, apenas um canal para o escoamento da produção artesanal local. Entretanto, quando se observa nos detalhes percebe-se a importância desse evento para a integração da comunidade; como espaço de convivência; de encontro e prosa. 


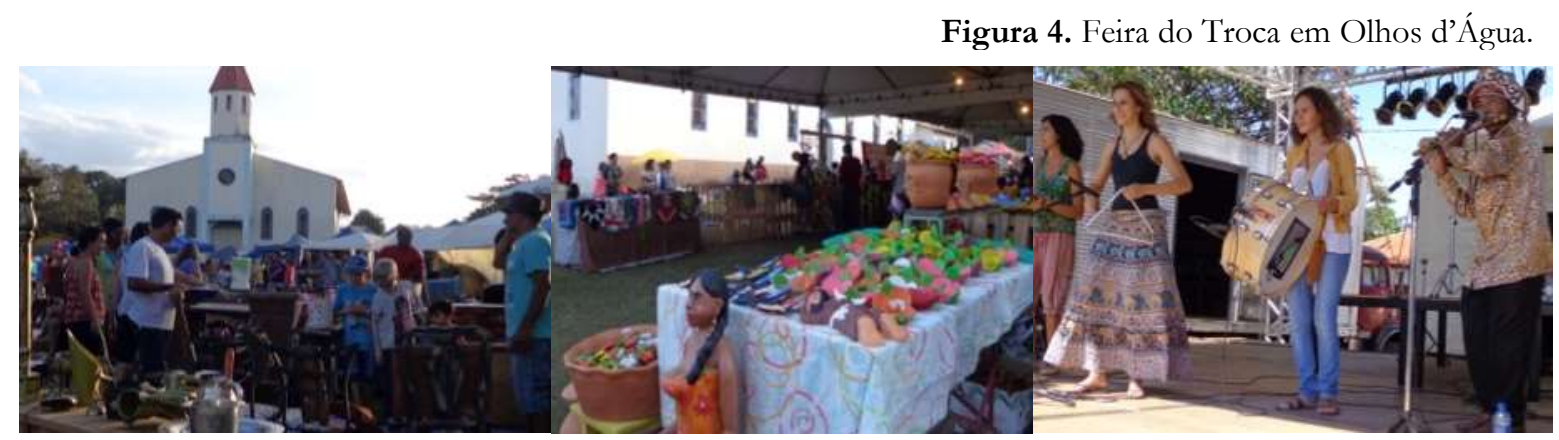

Fonte: Santos Neto. J. L. (2016). Legenda: da esquerda para a direita: exposição de produtos destinados à troca: artesanatos em cerâmica: e. apresentacão cultural.

A Feira contribui na definição da identidade da comunidade de Olhos d'Água e, ao mesmo tempo, é resultado de sua construção histórica na produção da paisagem e do seu território construído. Para Castells (2000), a construção de identidades forma-se a partir do que é fornecido pela história, geografia, biologia, instituições produtivas e reprodutivas; pela memória coletiva e por fantasias pessoais, pelos aparatos de poder e revelações religiosas. Nesse sentido, a comunidade continua em processo de construção de sua identidade ao preservar as construções históricas - igreja, casarios e praças -, mas também, ao manter a realização periódica das festas religiosas e profanas acompanhadas de comidas típicas e danças que eram realizadas desde os seus antepassados. É um patrimônio pois continua a pertencer a alguém, individual ou coletivamente na construção identitária dessa comunidade e na configuração estrutural de seu território. Esta concepção de patrimônio é discutida por Costa (2010).

Assim, pode-se depreender que a comunidade estudada tem se recriado ao produzir o seu território, por meio da elaboração de novos valores e elementos culturais, materiais ou simbólicos, que no universo pessoal e por meio da memória coletiva ressignificam-se através de expressões culturais como a Feira do Troca, o artesanato, a arquitetura, as festas e as comidas, que são elementos identitários e de tradições expressos como prática cultural.

\section{Para não concluir}

Pelo exposto, identifica-se na comunidade de Olhos d'Água que as expressões e representações locais constituem seu patrimônio cultural - material e imaterial. $O$ primeiro materializa-se nos casarios, no sítio histórico local, na culinária - representada pelo arroz com pequi -, e na produção artesanal - peças em argila, metal e pedra; toalhas produzidas nos teares familiares -; bonecas de pano; imagens sacras, etc.. E a paisagem bucólica - as cores, as formas e a disposição da arquitetura local - traduz um modo de vida pretérita resultante das relações do cotidiano rural goiano.

Quanto ao patrimônio imaterial tem-se nas festividades como a Feira do Troca, as Festas do Divino e da Quadrilha Junina as maiores representações identitárias local. Essas expressões e representações identificam a comunidade, que ganha relevo no contexto municipal com um modo de vida próprio. A comunidade encontrou nesses elementos o elo comum que a fortaleceu e propiciou a retomada de sua história e resistência no contexto municipal alexaniense. E é essa história e memória que precisavam ser festejadas e transmitidas às novas gerações. São esses referenciais que demandam ações públicas no sentido da sua valorização. Para Pelegrini (2009, p. 31), políticas voltada à preservação desse patrimônio pode resultar na "melhoria da qualidade de vida da população, pois a preservação das memórias e das identidades é uma demanda social tão importante quanto qualquer outra atendida pelo serviço público".

$\mathrm{Na}$ discussão aqui realizada, procedeuse com um recorte a partir da Feira do Troca pelo seu papel emblemático no resgate identitário da comunidade. Esse evento - bem como toda a preparação que o antecede - está atrelada ao cotidiano dos moradores como parte de suas vidas, de sua história e seguem com eles na sua compreensão e ralação com o mundo.

Desta forma, a construção da identidade local ultrapassa a noção materializada da feira. Está na produção agrícola e na colheita que é a base para a produção artesanal. Reside, também, nas ações que dão movimento e sentido de ser dos sujeitos sociais envolvidos no cotidiano que antecede a feira (plantar, colher, decidir 
Fernando Luiz Araújo Sobrinho Edilene Américo Silva

coletivamente o que produzir, até a confecção dos artesanatos) na preparação do evento e na sua realização propriamente. A feira é resultado dessa construção identitária, que por seu turno é fortalecida tanto pelo evento em si, quanto pelos processos que o antecedem. Mas, como a própria identidade está em permanente construção, a forma de apropriação e de sentidos atribuídos ao evento também são múltiplos e relacionam-se ao espaço e ao tempo. Esta discussão é trabalhada por Lima (2013).

Essa festa é construída por meio da participação da comunidade que, até os dias atuais, realiza como forma também de manter suas tradições e se autoafirmar para além da esfera municipal. Nela, também, os laços de pertencimento entre as pessoas e o lugar se fortalecem. Não obstante a nova aderência que a feira tenha recebido, ao longo do tempo, e que podem descaracterizar a sua essência, ela ainda constitui-se em singular elemento de fortalecimento comunitário (Silva, 2016).

Para Costa (2015, p. 35), essas aderências são consequência de "um processo de ressignificação dos lugares da cultura e da natureza em escala planetária". Para o autor essa ressignificação é denominada de "patrimonialização global". Esta se constitui em um processo que é definido como o "brusco movimento universal de espetacularização e banalização pela cenarização progressiva dos lugares promovida pela dialética Estado-mercado sobre a base das técnicas, da ciência e da informação" (Costa, 2015, p. 35).

Em Olhos d'Água, observou-se tanto o movimento da própria comunidade quanto de iniciativas da gestão pública municipal voltadas à inserção da Feira do Troca no calendário turístico do estado. A padronização das estruturas (bancas e tendas) voltadas à exposição das peças artesanais, a programação cultural, a organização e a divulgação do evento evidenciam um processo de espetacularização do evento voltado à visitação turística. A consequência marcante no sentido da Feira para a comunidade é que, na atualidade, predominam a oferta de artesanatos voltados apenas à venda, o que nega a proposta original da feira que pretendia ser um espaço de trocas.

Outro elemento observado é que a divulgação do lugar e do patrimônio material e imaterial desse distrito tem sido a estratégia de mercado utilizada para atrair o público consumidor. A visitação turística além de consumir os produtos ofertados na feira também acessa serviços de hospedagem e gastronomia disponível na comunidade.

Entretanto, esse patrimônio cultural de Olhos d'Água, que tem se tornado um produto em potencial ao desenvolvimento do turismo, precisa ser preservado (Silva \& Sobrinho, 2015). E esse modelo de turismo que tem se tornado hegemônico na sociedade contemporânea, exige precaução, pois transforma a cultura em mercadoria; e, faz com que o patrimônio, cada vez menos, represente a diversidade cultural dos povos e perca seu referencial de memória viva ao se tornar um produto, conforme discute Costa (2010).

Para o autor, a mercantilização desenfreada dos bens faz com que eles percam sua principal função que é a de esclarecimento e transforma-se num fetiche, incorporando um mundo de consumo e tornando-se peça central da máquina reprodutiva do capitalismo. Desse modo, o autor ratifica que a crescente mercantilização dessas expressões culturais envolve o patrimônio cultural em uma lógica dialética de uma construção destrutiva, onde os bens culturais do mundo têm seus sentidos metamorfoseados em prol da indústria cultural do turismo.

\section{Notas}

${ }^{\mathrm{i}}$ Os critérios que estabelecem essa regionalização estão indicados na Lei Complementar (Constituição Federal) no 94 , de 19 de fevereiro de 1998.

${ }^{\mathrm{ii}}$ Foi um projeto realizado, a partir de 1973, pela escola local, cujo objetivo era repassar os conhecimentos tradicionais de produção artesanal. Os alunos tinham, no currículo formal, aulas de produção artesanal diversa e seus professores eram os artesãos mais antigos que foram convidados a repassar esse conhecimento tradicional como forma de resgate cultural da comunidade (Entrevista realizada, 2015).

iii Entretanto, nas observações realizadas em atividade de campo em dezembro de 2015, identificou-se o predomínio de mais produtos voltados à venda em detrimento daqueles destinados à troca. Isso aponta para as inevitáveis mudanças nos propósitos originais da Feira.

\section{Referências bibliográficas}

Abdallah, A. (2015). Alexânia: a cidade dos meus sonhos. Alexânia, GO: Gráfica e Arte.

Angrosino, M. (2009). Etnografia e observação participante. Porto Alegre, RS: Artmed.

Arjona, M. (1986). Patrimonio Cultural e Identidad. La Habana, Cuba: Editorial Letras Cubanas.

Castells, M. (2000). A sociedade em rede - a era da Informação: economia, sociedade e cultura. São Paulo, SP: Paz e Terra.

Castilho, D. (2009). Modernização territorial e redes técnicas em Goiás. (Tese de doutorado). 
Universidade Federal de Goiás/UFG, Goiânia, GO.

Castriota, L. B. (2009). Patrimônio cultural: conceitos, politicas, instrumentos. São Paulo, SP: Annablume.

Claval, P. (2008). Uma, ou algumas, abordagem(ns) cultural(is) na geografia humana. In A. Serpa (Org.). Espaços culturais: vivências, imaginações e representaçôes. Salvador, BA: EDUFBA.

Costa, E. B. (2010). A dialética da construção destrutiva na consagração do patrimônio mundial. São Paulo, SP: Humanitas/FAPESP.

Costa, E. B. (2015). Cidades da patrimonialização global: simultaneidade totalidade urbana totalidade mundo. São Paulo, SP: Humanitas/FAPESP.

Haesbaert, R. (2004) O mito da desterritorialização: do fim dos territórios à multiterritorialidade. Rio de Janeiro, RJ: Bertrand Brasil.

Mohen, J. P. (1999). Les sciences du patrimoine: identifier, conserver, ressaurer. Paris, França: Éditions Odili Jacob.

Lima, L. N. M. (2010). A apropriação da cultura pelo turismo, a revalorização e a ressignificação das identidades culturais. GEOgraphia, 12 (24), pp. 150 - 166. doi: https://doi.org/10.22409/geographia.v $\underline{12 \mathrm{i} 24.387}$

Lima, L. N. M. (2013). O turismo, a reinvenção e a espetacularização na Procissão do Fogaréu da Cidade de Goiás (GO). Revista Brasileira de Ecoturismo, 6 (1), pp. 53 - 64. Recuperado de http://www.sbecotur.org.br/rbecotur/seer/ index.php/ecoturismo/article/view/ 390

Pelegrini, S. C. A. (2009). Patrimônio Cultural: consciência e preservação. São Paulo, SP: Brasiliense.

Sant'Anna, M. (2010). A cidade-atração: patrimonio e valorização de áreas centrais no Brasil dos anos 90. Cadernos PPG$A U / U F B A, \quad 3$, pp. Recuperado de https://portalseer.ufba.br/index.php/ppgau Larticle/view/1686/980

Santos, M. (2004). A natureza do espaço. São Paulo, SP: Hucitec.

Silva, E. A., \& Araújo Sobrinho, F. L. (2015). A Escala Local como Objeto de Análise Geográfica: a influência do eixo BrasíliaGoiânia na dinâmica territorial de Alexânia Goiás - Brasil. In Anais do II Congresso Internacional SETED-ANTE (pp. 13511362). Santiago de Compostela, Espanha: Universidade de Santiago de Compostela/USC.

Silva, E. A. (2016). A Feira do Troca na comunidade de Olhos d'Água (GO): da afirmação cultural a apropriação pelo turismo. Revista Brasileira de Ecoturismo, 9 (2), pp. 273 - 284. Recuperado de http://www.sbecotur.org.br/rbecotur/seer/ index.php/ecoturismo/article/view/ 946

Silva, E. A. (2017). A reconfiguraşão territorial de Alexânia (Goiás) a partir do eixo BrasiliaGoiânia. (Tese de doutorado). Universidade de Brasília/UnB, Brasília, DF.

Sobrinho, F. L. A. (2008). Turismo e dinâmica territorial no eixo Brasília-Goiânia. (Tese de doutorado). Universidade Federal de Uberlândia/UFU, Uberlândia, MG.

\section{Sites Acessados}

Instituto do Patrimônio Artístico e Cultural. (2017, 18 de maio). Carta de Fortaleza. Recuperado de

http://portal.iphan.gov.br/uploads/ckfinde r/arquivos/Carta de Fortaleza 1997.pdf

Prefeitura de Alexânia. (2016, 13 de janeiro). Recuperado

http://www.alexania.go.gov.br

Instituto Brasileiro de Geografia e Estatística, IBGE. (2016, 14 de fevereiro). População e Indicadores Sociais. Recuperado de http://www.cidades.ibge.gov.br/xtras/perfil php? lang $=$ \&codmun $=520030$

Instituto Mauro Borges, IMB. (2015, 02 de abril). PIB Trimestral do Estado de Goiás: $4^{\circ}$ trimestre - 2014. Recuperado de http://www.imb.go.gov.br/pub/pib/pibgot rimestral/ pibgo4tri2014.pdf

\section{Como citar este artigo}

Araújo Sobrinho, F. L. \& Silva, E. A. (2018). Patrimonialização e afirmação cultural no distrito de Olhos d'Água, Goiás, Brasil. PatryTer, (1), 1, pp. 57-67.

DOI: https://doi.org/10.26512/patryter.v1i1.7089 